\title{
A Survey on Vehicular Ad-Hoc Networks Routing Protocols: Classification and Challenges
}

\author{
TASSOULT Nadia \\ Computer Science Department \\ Batna 2 University, Algeria \\ doctoratas16@gmail.com \\ AMAD Mourad \\ LIMPAF LABORATORY, Computer Science Department \\ Bouira University, Algeria \\ amad.mourad@gmail.com \\ MOUMEN Hamouma, KALLA Hamoudi \\ Computer Science Department \\ Batna 2 University, Algeria \\ moumenh@gmail.com, hamoudi.kalla@univ-batna2.dz
}

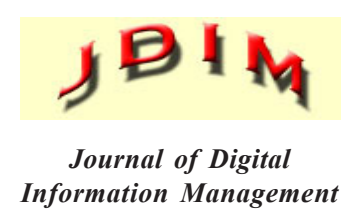

Information Management
ABSTRACT: The Vehicle ad hoc Networks (VANET) are attracting more and more manufacturers and researchers' attention. Many challenges must be addressed before VANETs can be successfully deployed. The most challenging issue in VANETs is designing of routing mechanisms and efficient medium access control protocols so that safety related and other application messages can be timely and reliably disseminated through VANETs. The aim of VANET routing protocols is establishing of an efficient route between network nodes that should adapt to the rapid changes in the network topology. However, routing protocols in VANET is a challenging issue, mainly due to the rapidly changing topology of vehicles and frequent fragmentation in the network. In this work, we review the most frequent routing protocols for VANETs and then we provide a taxonomy of these protocols based on the used relay selection technique. We compare and discuss these routing protocols according to different criteria. Moreover, we discuss several issues and prerequisite that should be considered when designing VANETs routing. Finally, we highlight the most important aspects and future directions that could be explored in the design of a new Geocast routing solution for vehicular routing algorithms as a contribution for further work.

Subject Categories and Descriptors: [C.2.2 Network Protocols]; Routing protocols: [C.2.1 Network Architecture and
Design] Network topology

General Terms: Vehicle Adhoc Networks, Routing Protocols

Keywords: Vehicle Ad hoc Networks, Routing Protocols, Topology, Geocast Routing, Challenges, Optimisation

Received: 24 November 2018, Revised 24 February 2019, Accepted 12 March 2019

Review Metrics: Review Scale- 0/6, Review Score-4.72, Interreviewer Consisteny- $86.2 \%$

DOI: $10.6025 / \mathrm{jdim} / 2019 / 17 / 4 / 227-244$

\section{Introduction}

Wireless communication for Vehicular ad hoc networks (VANETs) has drawn extensive attention for their promise to contribute to a safer, more efficient, and more comfortable driving experience in the future. This type of communication consists of mobile nodes capable of communicating with each other (i.e. Vehicle to Vehicle Communication, V2V communication) and with the static infrastructure (i.e. Vehicle to Infrastructure Communication, V2I communication). VANETS are appropriate networks that can be applied to intelligent transportation systems [1]. The novelty of VANETs with respect to other ad hoc networks has been highlighted, and specified VANET re- 
quirements are detailed in [2] and [3].

In VANETs, vehicles are equipped with on-board units (OBUs) and fixed communication units (road-side units, RSUs) and are placed along the road. Applying short range wireless technology based on IEEE 802.11, multi-hop communication facilitates information exchange among network nodes that are not in direct communication range [4]. However, as the network scale of VANETs is expected to be very large, the open-medium nature of these networks and the high-speed mobility of a large number of vehicles make necessary the establishment of an efficient route between network nodes that should be adapted to the rapidly changing topology of vehicles in the network.

There are a plethora of VANET routing protocols. Most are designed to handle a special prerequisite or condition. Despite the special condition that these routing protocols are addressing, there is no standard methodology to validate their performance. Most of the designed routing algorithms are verified using simulation results, and a few are analyzed using a mathematical model. To evaluate performance analysis in VANET, the major challenge is to provide a sufficient level of details to ensure realistic traffic scenarios and driving behaviour.

In the following, we detail the different criteria that are used to classify the different categories of routing protocols in the field. We briefly describe each protocol, highlighting its assets and drawbacks, and then provide an intuitive classification table that allows readers to easily understand each protocol's characteristics. Our objective is to help readers to better compare the different solutions available in the literature, and find the one tailored to their needs.

In this paper, we seek to provide a survey that might summarize the existing VANETs routing algorithms having a general knowledge related to vehicular communications. Many other surveys have been mainly published for VANETs routing in the literature $[5,6,7,8,9,10,11,12,13,14$, $15,16,17,18,19,20,21,22,23$ ] aiming to explore many essential points in the field. However, most of these had usually specified a limited class of VANETs issues such as a subcategory of routing algorithms for a sub-area of VANET applications [24, 25, 26, 27, 28, 29, 30, 31, 32]. Our survey aims to offer a large set of general surveys to the novice researchers and some understanding on the current research and the future directions that could be explored in the design of vehicular routing algorithms. It is therefore targeted to readers curious to discover this field of research and to experts in this area.

The remainder of the paper is organized as follows. Section 2 gives an overview of Vehicular ad hoc Networks. Moreover, we introduce the VANET architecture and its characteristics, we describe the different types of applications for VANETs, and a set of specifications for Wireless Access in Vehicular Environment and standards.
Next, we present the different classes and the most sig 5 points out some open issues and discusses challenges in VANETs. Finally, we provide in Section 6 concluding comments and we suggest promising new research directions remaining in this field.

\section{Overview of Vehicular Ad Hoc Networks}

Vehicular ad hoc networks (VANETs) are a subset of mobile ad hoc networks (MANETs). We sharing some of the same limitations, such as lack of infrastructure and limited communications range. They have several dissimilarities that make VANETs a much different research area. Therefore, research done on MANETs are not completely applicable to VANETs. VANETs are hosted on vehicles and fixed infrastructure points, so power and space for radio, storage, and for processing units is not an issue, and the number of vehicles and their speed make scalability difficult [33].

VANET is based on a short-range wireless communication between vehicle to vehicle and some roadside infrastructure. Moreover, a large number of Certification Authorities (CAs) will exist, where each CA is responsible for the identity management of all vehicles registered in its region (e.g., national territory, district, country) [34].

In next subsection, we describe the most common entities that appear in VANETs.

\subsection{Common VANET Entities}

Two different environments are generally considered to exist in VANETs (see Figure 1).

\subsubsection{Infrastructure Environment}

The entities of the network can be permanently interconnected. This part of the network is mainly composed of those entities that manage the traffic or offer an external service. On one hand, manufacturers sometimes consider within the VANET model and they identify uniquely each vehicle. On the other hand, the legal authority is commonly present in VANET models. Despite the different regulations on each country, it is habitually related to two main tasks: vehicle registration and offense reporting. Every vehicle in an administrative region should get registered once manufactured. Trusted Third Parties (TTP) are also present in this environment. They offer different services like credential management. Both manufacturers and the authority are related to TTPs because they eventually need their services (e.g. for issuing electronic credentials).

\subsubsection{Ad-hoc Environment}

Ad-hoc communications are established from vehicles. Generally, they are equipped with three different devices. Firstly, they are equipped with a communication unit (OBU, On- Board Unit) that enables Vehicle-to-Vehicle (V2V) and Vehicle-to-Infrastructure (V2I, I2V) communications. On the other hand, they have a set of sensors to measure their own status and its environment. These sen- 


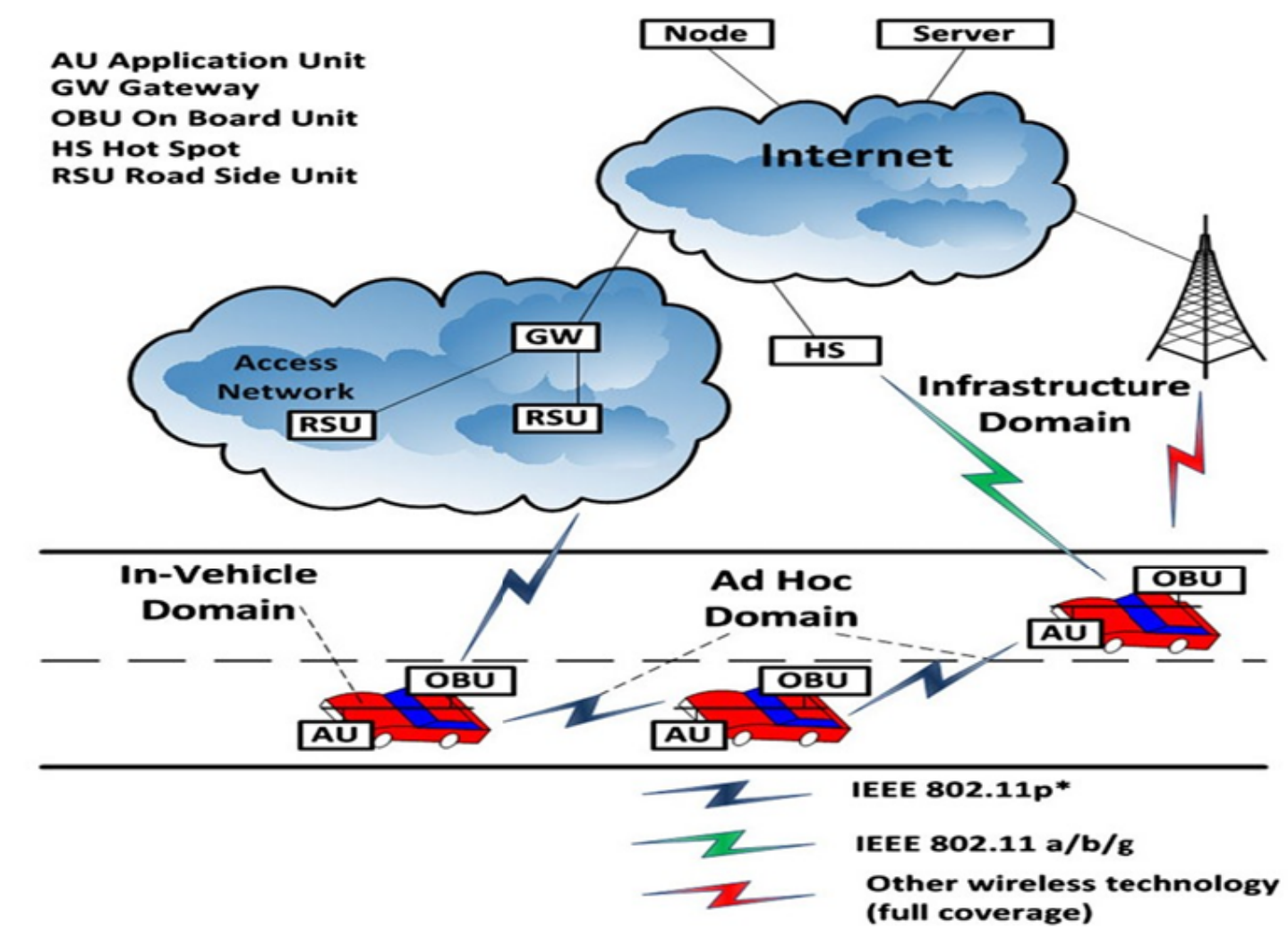

Figure 1. C2C-CC reference architecture [35]

sorial data can be shared with other vehicles to increase their awareness and improve road safety. Finally, a Trusted Platform Module (TPM) is often mounted on vehicles. These devices are especially interesting for security purposes, as they offer reliable storage and computation. In this kind of communications, vehicles move at a relatively high speed and, on the other hand, the high amount of vehicles present in a road could lead to an enormous network. Thus, a specific communication standard, called Dedicated Short Range Communications (DSRC) has been developed to deal with such requirements. This standard specifies that there will be some communications devices located aside the roads, called Road-SideUnits (RSU). In this way, RSUs become gateways between the infrastructure and vehicles and vice versa.

\subsection{Applications of VANETs}

The main purpose of communication in vehicular networks, either in vehicle-to-vehicle (V2V) or vehicle-to infrastructure (V2I), is to provide safety and/or non-safety services. In safety applications, vehicles broadcast safety messages to other vehicles within a small range such as 300 meters [36]. Safety messages are given the highest priority in vehicular communication networks. However, even with the consideration of priority, when a vehicle broadcasts a safety message, a transmission collision may occur due to a transmission of other safety messages that needs to be sent with priority. Thus, an efficient medium access methodology is needed to enhance the collision avoidance process. Within this type of application, messages interchanged over VANETs have different natures and purposes. Considering this, different communication patterns can be identified:

\subsubsection{V2V Beaconing}

Beacon messages are sent periodically to nearby vehicles. They contain the current speed, heading, braking use, etc. of the sender vehicle. These messages are useful to increase neighbour awareness. Beacons are only sent to one-hop communicating vehicles, i.e. they are not forwarded. In fact, they are helpful for routing protocols, as they allow vehicles to discover the best neighbour to route a message.

\subsubsection{I2V/V2I Warning}

These messages are sent either by the infrastructure (through RSUs) or a vehicle when a potential danger is detected. They are useful for enhancing road safety. As an example, a warning could be sent by the infrastructure to vehicles approaching to an intersection when a potential collision could happen.

Another application for vehicular networks is the multimedia services. For example, a vehicle might download video, audio, or maps with certain quality-of-service (QoS) the requirement from a roadside unit (RSU) or from another vehicle in a cooperative mode. If these applications are provided commercially, certain QoS should be guaranteed. This makes designing an efficient medium access control (MAC) protocol in vehicular networks essential. 


\subsection{Standards}

The IEEE 802.11P task group has defined a set of specifications for Wireless Access in Vehicular Environment (WAVE) to fulfill the requirements of such challenging environment. The Federal Communication Commission (FCC) allocated $75 \mathrm{MHz}$ of licensed spectrum for Dedicated Short Range Communications (DSRC) at $5.9 \mathrm{GHz}$ band to be used exclusively for vehicle-to vehicle (V2V) and vehicle to infrastructure (V2I) communications [37]. IEEE 802.11P operates in the frequency band of 5.85$5.925 \mathrm{GHZ}$, within which the DSRC spectrum is structured into seven $10 \mathrm{MHz}$ wide channels. The control channel $(\mathrm{CCH})$ is exclusively reserved for safety-related communications like beacons and event-driven messages whereas up to six service channels ( $\mathrm{SCHs}$ ) are used for non-safety data exchange. IEEE802.11P uses the same medium access mechanism of IEEE 802.11e, named Enhanced Distributed Channel Access (EDCA) [34] (see Figure 2).

In IEEE 802.11P, the channel time is divided into synchronization periods of $100 \mathrm{~ms}$ each, consisting of equal length alternating $\mathrm{CCH}$ and $\mathrm{SCH}$ intervals. The coordination between channels is achieved through the use of the Coordinated Universal Time (UTC) offered by a global navigation satellite system. DSRC is known as IEEE 802.11p WAVE (Wireless Access in Vehicular Environments), Within IEEE 802.11. IEEE 802.11p WAVE is a part of a group of standards related to all layers of protocols for DSRC based operations. The standard is limited by the scope of IEEE 802.11, which is strictly a MAC and PHY level standard that is meant to work within a single logical channel [4] as shown in Figure 3.

\subsubsection{IEEE 1609 Standards}

The IEEE 1609 working group has developed and issued a series of Trial-Use Standards for Wireless Access in Vehicular Environments (WAVE). Vehicle-to-vehicle (V2V) and vehicle-to-infrastructure (V2I) communication are accomplished using Dedicated Short Range Communication (DSRC), which is covered in the IEEE Standard P802.11p and the IEEE Standard 1609 series. This standard has four main parts, covering the application layer [39], security services [40] and multichannel operation [41], and network services [42]. IEEE 1609 uses IEEE P802.11p and DSRC as the WAVE protocols. Two devices are defined in the 1609 standard: a roadside unit (RSU) and an on-board unit (OBU) [39].

\subsubsection{Physical Layer Standard}

IEEE 802.11p [43] is a draft IEEE standard for vehicular communication as an amendment to the standard IEEE 802.11 [44]. The standard $802.11 \mathrm{p}$ is specifically for wireless access in vehicular environments, it covers many aspects of the physical and MAC layer protocols for this case. Two different classes of channels are described for use in DSRC/WAVE. The first channel class is the control channel, referred to as $\mathrm{CCH}$, which is a single channel reserved for short, high-priority application and system control messages [41].

\subsubsection{Network Layer Standards}

WAVE supports two different network-layer protocols, IPv6 and the WAVE short message protocol (WSMP). IPv6 traffic is not allowed on the CCH, but WSMP traffic is allowed on both the $\mathrm{CCH}$ and the SCHs. The WSMP does not use a MAC address or IP address to identify the source or destination. Instead, WSMP uses an Application Class IDentifier (ACID) and an Application Context Mark (ACM) to identify the application class and the instance of the application class, respectively [40]. A WAVE Short Message (WSM) is the format used for sending messages using the WSMP. WSMP also serves as the transport layer protocol, replacing TCP and UDP for these messages. WSMs may be sent on either the $\mathrm{CCH}$ or the SCHs.

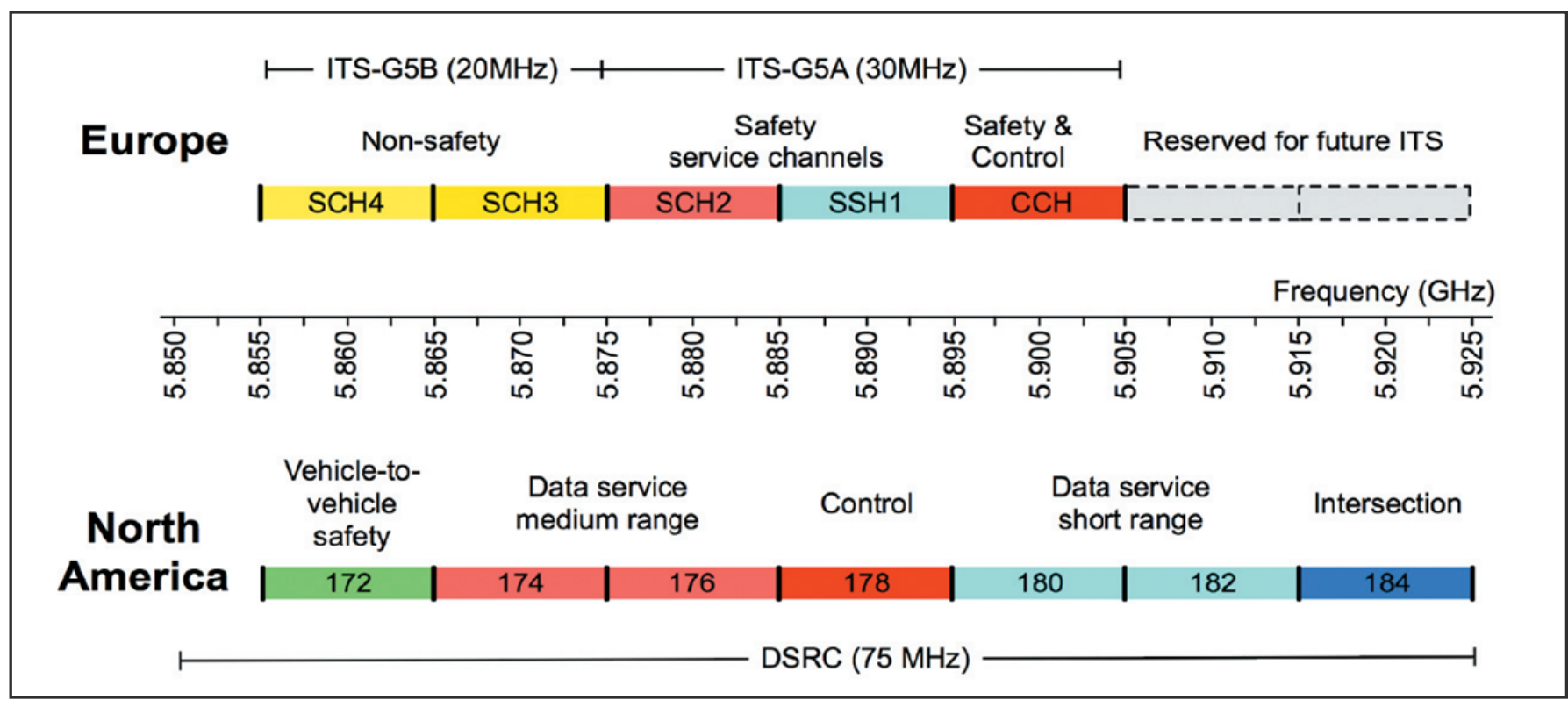

Figure 2. DSRC frequency allocation in Europe and North America [38] 


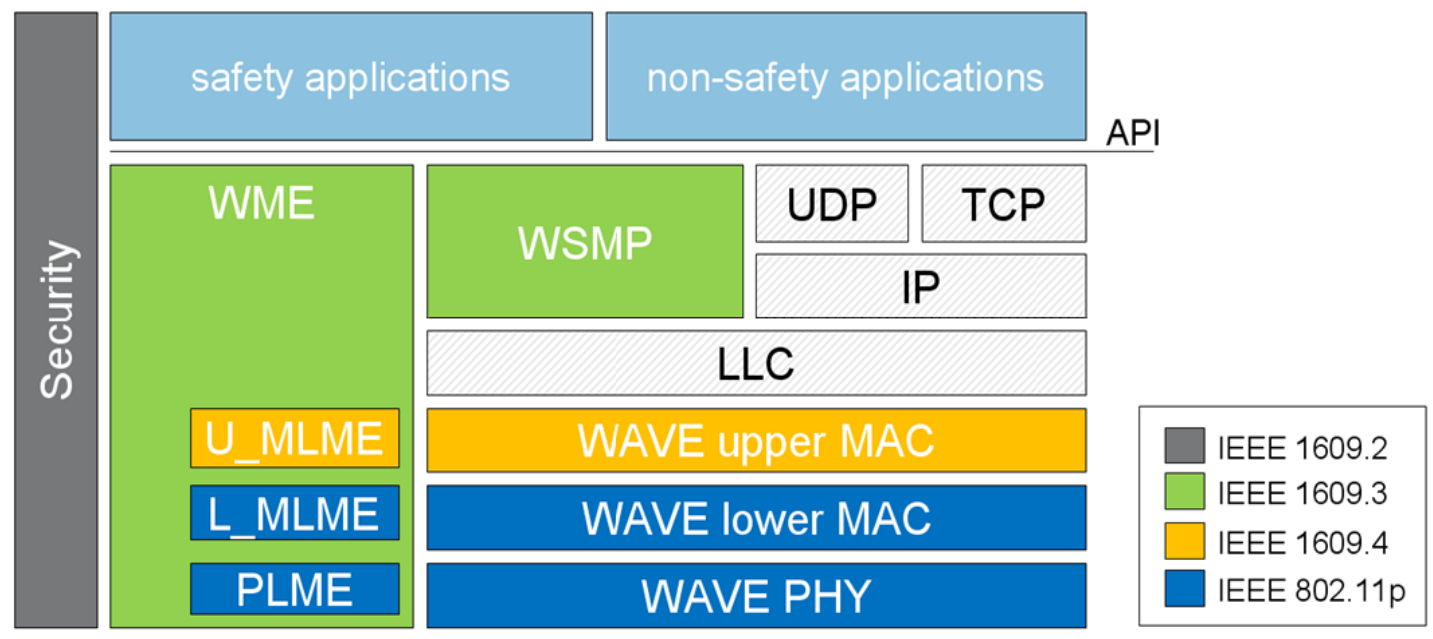

Figure 3. DSRC standards and communication stack [4]

\begin{abstract}
2.3.4 Medium Access Control (MAC) Layer Standard Packet collisions and poor radio reception are the primary causes for nodes not receiving data sent over a wireless medium. DSRC uses carrier sense multiple access/ collision avoidance (CSMA/CA) to reduce the number of collisions and to allow fair access to the medium. Each node, using CSMA/CA, must first sense the medium to determine if the medium is idle or busy. When the medium is idle, nodes wait for a fixed arbitration inter-frame space- time plus a random time between zero and the minimum contention window value before sending data. Transmission prioritization in DSRC is scheduled using Enhanced Distributed Channel Access (EDCA) based on the IEEE Standard 802.11e [44].
\end{abstract}

\section{Routing in Vanets}

Vehicular networks differ from conventional ad hoc wireless networks by not only experiencing rapid changes in wireless link connections, but also having to deal with different types of network densities [9, 45]. Moreover, VANETs are expected to handle a wide range of applications ranging from safety to leisure. Consequently, routing algorithms should be efficient and should adapt to vehicular network characteristics and applications, permitting different transmission priorities according to the application type (safety related or not). Different routing protocols approaches for VANETs are proposed to fit different applications. In this section, we illustrated the different available approaches for the development of routing strategies. In Figure 4, we present our classification of VANETs routing. As shown in the figure (see Fig. 4), the routing protocols fall within two categories of topology-based and location-based routing. Moreover, we summarize the characteristics of representative routing protocols that have either been used or designed specifically for VANETs.

\subsection{Topology-based Routing Protocols}

Topology-based routing uses the links information in the network to perform packet forwarding. In the literature, various classifications of routing protocols, according to different aspects, exist. We take back the traditional one, which considers the network structure, where protocols are categorized under three main classes, namely proactive routing protocols, reactive routing protocols and hybrid routing protocols. These routing protocols suffer from routing route breaks because of the regular changes of the links information in the network.

We present in this section some topology-based routing protocols.

\subsubsection{Proactive Routing Protocols}

This kind of routing is also called as table-driven routing. Within this approach, each node maintains one or many tables that contain routing information to every node in the network. The main advantage of the approach is that there is no route discovery since all the possible paths connecting each node in the network to any other ones are maintained in the background. In this routing approach, and in order to react to changes in the network topology and keep up-to-date routing information, each node of the network propagates routing updates periodically to their neighbors. Several protocols have been proposed, in the following, we present the most popular ones.

OLSR (Optimized Link State Routing) [46] is one of the most important ad hoc proactive routing protocols; it is an update of a pure link state routing protocol. The routing is applied to vehicle networks in the city environment. OLSR introduces the concept of Multi-Point Relay (MPRs). The use of MPRs minimizes flooding of control traffic. Indeed only multipoint relays forward the control messages. This technique significantly reduces the number of retransmissions of broadcast control messages [47].

DSDV (Destination Sequenced Distance Vector) [48], the routing belongs to a family of unicast topology based and table-driven routing algorithms. In DSDV, each node seeks to maintain a routing table to reach any other node in the 
destination. To maintain the consistency of the routing table in a topology which quickly changes, every node of the network transmits periodically its routing table to their direct neighbors. The node can also transmit its routing table if the contents of the latter undergo significant changes with regard to the last sent contents. The DSDV protocol aims to limit the traffic caused by all these updates.

FSR (Fisheye State Routing) [49] is an efficient unicast link-state routing. It maintains a topology map at each node and propagates link-state updates with only the immediate neighbors. Furthermore, the link-state information is broadcast in different frequencies for different entries depending on their hop distance to the current node. Entries that are further away are broadcast with a lower frequency than ones that are closer. The reduction in broadcast overhead is traded for the imprecision in routing. However, the imprecision gets corrected as packets approach progressively closer to the destination.

\subsubsection{Reactive Routing Protocols}

Reactive routing is an on-demand routing in which routes are not updated with changing topology of the network. The route discovery is initiated only when a source node wants to communicate or send data to another node in the destination. Reactive routings aim to reduce the burden on the network since only the routes currently in use need to be maintained. The drawback of this kind of algorithms is their latency because of the additional time needed in establishing a route.

We present below the most popular reactive routing protocols in ad hoc networks.

AODV (Ad Hoc On-Demand Distance Vector) [50] is a source initiated on-demand routing protocol designed for general purpose mobile ad hoc networks and do not maintain routes unless it is needed. The routes created by AODV can break very frequently due to the dynamic nature of the mobility involved. In AODV protocol, route reply packets carry the destination address. Each node broadcasts only the first route request message it receives. In scenarios with a small number of network flows, AODV can reduce the overhead. Authors of [51] have shown that AODV is unable to quickly find, maintain, and update long routes in a VANET.

DSR (Dynamic Source Routing) [52] is a unicast on-demand routing algorithm. Also, it is a source routing in which the routes are created only when they are required. In the routing, route reply packets carry the address of each node along the route. With DSR, an alternative route can be used when some link in the current route breaks. In a network with low mobility, this is advantageous over AODV since the alternative route can be tried before DSR initiates another flood for route discovery. Unlike to AODV, in DSR route reply packets carry the full routing information. Many works have been done to evaluate the performance of ad hoc routing protocols in the context of VANETs

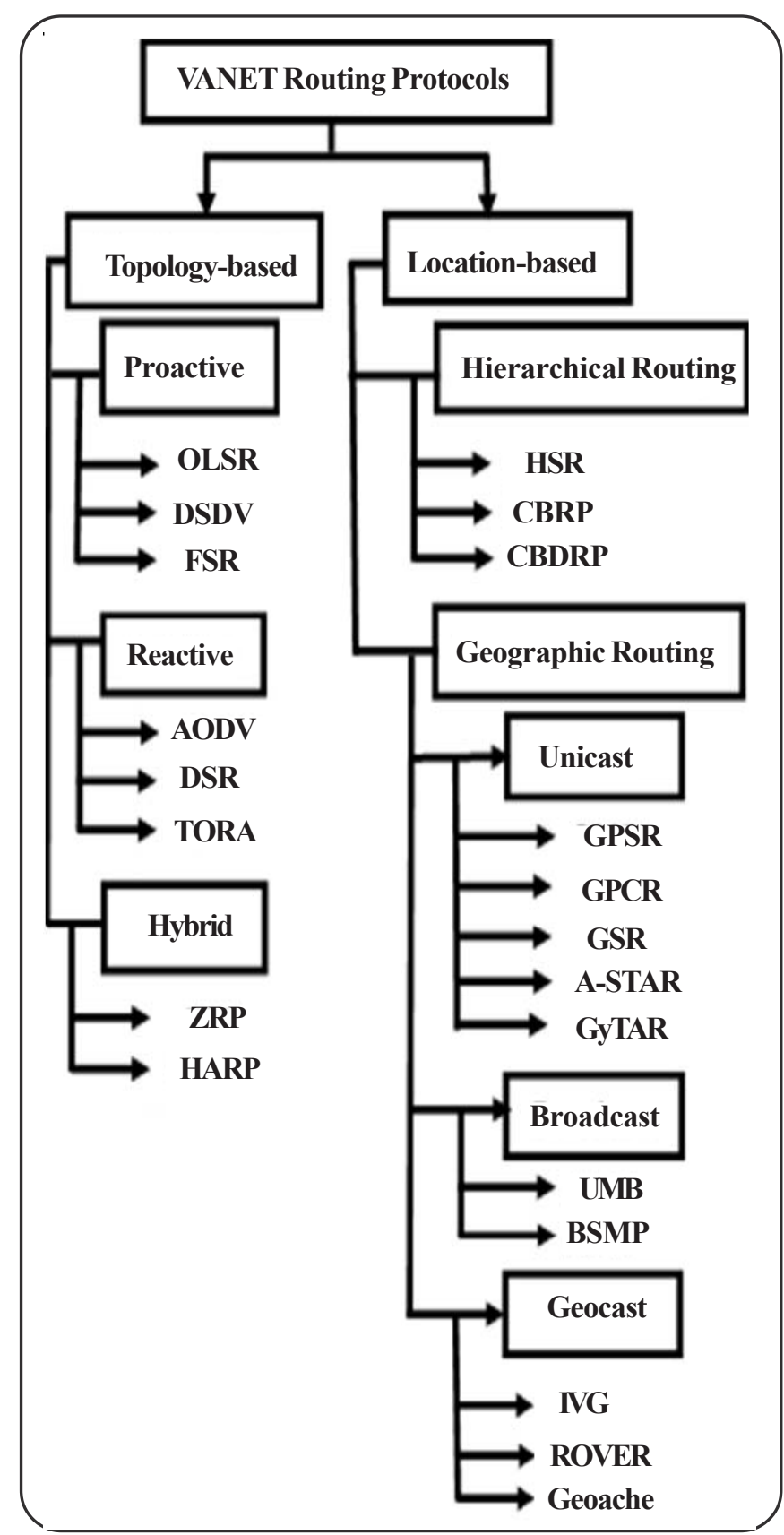

Figure 4. Classification of routing protocols in VANETs

$[53,33,51]$ within different traffic conditions. From their simulation, it is shown that AODV and DSR suffer from highly dynamic mobility of the nodes in the network since they tend to have poor route convergence and low communication throughput.

TORA (Temporally Ordered Routing Algorithm) [54] is a unicast routing algorithm. The protocol aims to provide a route to all the nodes in the network and that it has reduced far-reaching control messages to a set of neighboring nodes. However, the maintenance of these routes can be overwhelmingly heavy in the context of VANETs. The authors of [19 27] have evaluated AODV, DSR, FSR, and TORA in city traffic scenarios. The simulation results showed that AODV has better performance and lowest control overhead. However, since source routes change 
frequently due to high nature mobility nodes in the network DSR suffers from a very high delay and a yet higher route overhead than AODV compared to FSR. Thus the performance of the evaluated routing protocols degrades as densities of the network increase, resulting in a scalability problem especially highly dynamic ad hoc network such as VANETs.

\subsubsection{Hybrid Routing Protocols}

This type of routing protocol switches from proactive mode to reactive mode. We describe in the section the most common routing protocol of the approach.

ZRP (Zone-Based Hierarchical Link State Routing Proto$\mathrm{col}$ ) [55] is a unicast hybrid routing protocol. ZRP defines around every node a zone which contains the nearby nodes. Proactive and reactive algorithms are used by the node to forward packets, respectively, in and except the zone. It is essentially a zone-based routing. Within the intra-zone a proactive routing is performed using a linkstate algorithm. However, a reactive routing is to be performed with nodes interzone. In ZRP every node manages its zone. For routes inside of the zone the route is discovering reactively, for routes outside of the zone node transmit a route request to the others zones. This routing aims to combine the advantages of both approaches. However, ZRP is not efficient enough in case of urban environment and high mobility of nodes such as VANET.

HARP (Hybrid Ad hoc Routing Protocol) [56] is a unicast hybrid routing protocol. The HARP protocol aims to ameliorate the delay by implementing route discovery between the source node and the destination one. This protocol selects the best route according to constancy proprieties [57]. Depending on the position of the destination node, HARP performs the routing on two phasis: intra-zone and inter-zone. HARP uses reactive and proactive algorithms in interzone and intrazone. To simplify the routing algorithm and makes the design modular, HARP tries to search and maintain a route between the source node and the destination node and leaves the generation of the topology to DDR (Distributed Dynamic Routing) [57, 58]. Contrary to ZRP, the flooding within the HARP protocol is limited to the subset of transfer nodes in each zone to reduce the bandwidth usage and the energy consumption of non-forwarding nodes. In addition, early path maintenance is applied in the HARP protocol which is more suitable for priority classes.

\subsection{Location-based Routing Protocols}

To overcome the limitation of the topology-based routing, a new kind of routing strategy, based on location information, has been developed. Location-based routing protocols use information about the geographic coordinates or relative positions of nodes to generate an efficient route through the network. In such a strategy of routing, each node decides where to forward each received packet. In this way, creating and maintaining the global route from a source node to a destination node is not necessary. The work of[8] has shown that routing algorithms using location information can adapt to the high mobility of nodes in high way situations. This location-based routing approach adapts well to the dynamic nature of large scale adhoc networks such as VANETs. We classify the routing protocols of this category into two main categories: Hierarchical routing protocols and geographic routing protocols.

\subsubsection{Hierarchical Routing Protocols}

This kind of routing protocol is also called a cluster-based routing. It aims to create a virtual network by structuring the network hierarchically in order to provide scalability. Each cluster has a manager node called cluster head $\mathrm{CH}$ ) responsible for the coordination between its members and the other clusters of the network.

In the following, we present two of the most important protocols of the approach.

HSR (Hierarchical State Routing) [59] is one of the most significant proactive hierarchical routing protocols. HSR defines several levels of hierarchy in nodes. The network is partitioned on many groups which are divided into subgroups and so on. A representative for every group is elected. The representatives of the groups in a level "i" become members of the level " $i+1$ ". The nodes of the same group exchange routing information. The groups of the same level communicate by using a gateway. Every node has a hierarchical address dialed the numbers of the groups on the way from the root to the node in the destination and this hierarchical address is enough for disseminating the data packets in a destination, independently of the location of the source, simply by using the table of the protocol HSR.

CBRP (Cluster Based Routing Protocol) [60] is a unicast Hierarchical Routing Protocol. In CBRP the network is partitioned to clusters. The reactive aspect of the protocol appears when a node wants to transmit data packets to another node in the destination. In this routing, the cluster training is very simple. Indeed, the node with the smallest identifier is elected as leader of the cluster. Nevertheless, to avoid frequent changes in the structures of clusters, a member node is not authorized to challenge the leader even if its identifier is smaller. Two leaders of clusters should not have a direct link between them. If, afterward of a change of topology occurs, then, it is necessary to reconstruct clusters and that possessing the lowest identifier is elected as leader. Nodes being at the extremities of clusters are called getways which allow to relieving the information between clusters.

CBDRP (cluster-based directional routing protocol) [61] is a multicast Clustering Routing Protocol mainly proposed for VANET. The CBDRP protocol is suitable for high-speed vehicles moving at highways where minimum latency is needed. Within CBDRP, the source sends the data to its cluster-head to establish a communication link. To forward packets, the current cluster-head selects another cluster head according to the moving direction of 
vehicle. If the cluster-head cannot be reached, the vehicle is obliged to broadcast the packet with a traditional approach. As soon as the packet arrives at the cluster head of the cluster in which the destination node lies, this latter transmits the packet to the destination node. The authors of [61] have shown that CBDRP has high packet delivery ratio, high link stability, and low latency. The principal advantage of CBDRP protocol is the reduced traffic overhead due to the direct transmission of the requested packet to cluster heads. However, the cluster performance is highly influenced by the dynamic change of the cluster head. Moreover, the delay rises when the number of clusters increases.

\subsubsection{Geographic Routing Protocols}

Geographic routing allows for communication and dissemination of messages to all nodes in a geographic area. It uses neighboring position information to perform packet forwarding. Geographic routing assumes each node knows its location, and the sending node knows the receiving node's location by the increasing popularity of Global Position System (GPS) unit from an onboard Navigation System and the recent research on location services. Since geographic routing protocols do not exchange linkstate information and do not maintain established routes like proactive and reactive topology-based routings do, they are more robust and promising to the highly dynamic environments like VANETs. The routes are determined based on the geographic location of neighboring nodes as the packet is forwarded. Geographic routing is subclassified into three categories of the unicast routing protocols, broadcast routing protocols and geocast routing protocols. We describe these three subcategories in the following sub-sections.

Unicast Routing Protocols: The routing protocols of this category aims to reduce the overhead by transporting a single data packet to the destination node without any duplication. Unicast routing allows for one node to send messages to a target node in a precise known location or an approximate location within a specified range in the network.

Broadcast Routing Protocols: Broadcast is a routing mechanism that is used to find an efficient route to the node destination during the routing discovery phase of unicast routing protocols. Broadcast protocols are designed to communicate important safety messages to all nodes in the network.

\section{Geocast Routing Protocols}

Rely on location-based multicast routing. The main idea of such routing is to deliver the data packet from a source node to all other nodes within a specified geographical region called ZOR (Zone of Relevance). Geocast routing can be implemented with a multicast service by simply defining the multicast group to be a certain geographic region. It aims to limit the message overhead and network congestion by using directed flooding and restricting the flooding inside a defined forwarding zone.
Recently, many routing protocols specific to VANETs have been proposed. This section describes the most common geographic routing protocols proposed in the literature.

GPSR (Greedy Perimeter Stateless Routing) [62], routing belongs to a family of Non-DTN routing algorithms (non-Delay Tolerant Network). It is a unicast routing protocol that utilizes a position-based and a greedy forwarding strategy for sending messages toward a known destination to provide vehicle-to vehicle communication. In GPSR, each node forwards its packet to its immediate neighbor that is geographically closest to the destination node. The forwarding strategy can fail if there are no nodes in the direction of the destination. When this routing error occurs, GPSR uses a recovery strategy called perimeter mode to cope with the problem and to get out of the local minimum. GPSR works best in a free open space scenario. The work of [63] has shown that GPSR achieves better results in a highway scenario compared to DSR. The protocol suffers from several problems when applied it to city scenarios for VANETs as it is shown by the authors in $[14,33,63]$.

GPCR (Greedy Perimeter Coordinator Routing) [64] is an hybrid routing of non-DTN and DTN approach that includes the greedy mode and the perimeter one. GPCR has been designed to deal with the challenges of city scenarios. It does not rely on a street map to determine whether a node is located at a junction, the only places where actual routing decisions are taken. Therefore data packets should be forwarded to nodes at an intersection (called Coordinator) in the street rather than forwarding them across the junction to a node that is already past the intersection. GPCR forwards messages using a restricted greedy forwarding algorithm. When the greedy strategy reaches a local optimum, GPCR uses a restricted greedy forwarding algorithm and a repair strategy for routing as long as the nodes are in a street towards a destination since no neighbor exists which is closer to the destination than the intermediate node itself. The authors of the paper have shown that GPCR has a higher delivery rate than GPSR with a larger average number of hops and slight increase in latency.

GSR (Geographic Source Routing) [65] is a promising geographic VANET unicast routing that tries to overcome some of the disadvantages of the geographic routing designed for MANETs when applied to VANETs in city environments. It combines position-based routing with topological knowledge. GSR uses a static street map in city environments to avoid these problems. Using a static street map and location information about each node, GSR computes a route to a destination by forwarding messages along streets. It uses a Reactive Location Service (RLS) to obtain the destination position. Using this information, the sender determines the junctions that have to be traversed by the packet using the Dijkstra's shortest path algorithm. Forwarding between junctions is then done in a position-based fashion. The simulation results dem- 
onstrate that GSR has better average delivery rate, smaller total bandwidth consumption and similar latency of first delivered packet with DSR and AODV.

A-STAR (Anchor-based Street and Traffic-Aware Routing) [66] is a greedy location-based unicast routing protocol designed for IVC in such city environments. It uses static vehicular traffic information based on city bus routes as a strategy to find routes with a high probability for delivery to find a path from source to destination. In A-STAR, the message forwarding is done without considering vehicle direction. The protocol is compared to GSR and GPSR. The packet delivery ratio of A-STAR is lower than GSR and GPSR with or without recovery. Similar to GSR, ASTAR uses a static street map to route data packets around potential radio obstacles. However, A-STAR differs from GSR by computing the sequence of junctions paths (anchors) through which data packets must pass to reach its destination with traffic awareness. Unlike to GSR and GPSR, A-STAR incorporates traffic awareness by using statistically rated maps or dynamically rated maps to establish an anchor path with high connectivity for data packet delivery. With traffic awareness, A-STAR shows the best performance compared to GSR and GPSR, because it can select paths with higher connectivity for packet delivery. Thus, the ratio of data packets delivered by ASTAR is better compared to GSR. In addition, A-STAR utilizes a new local recovery strategy for the data packets routed to a local minimum that is more suitable for a city environment than the greedy algorithm of GSR and the perimeter-mode of GPSR.

GyTAR (improved greedy routing protocol) [67] is an intersection-based geographic routing protocol capable to find robust routes within city environments. It relays data in the network considering the real-time road traffic variation and urban environment characteristics taking into account information about vehicles speeds and directions. GyTAR aims to efficiently use the wireless bandwidth by limiting the control message overhead, and to route data packets from source nodes to destination ones with a reduced end-to-end delay and low packet loss. In the paper, a comparison has been performed between GSR and GyTAR. The simulation shows that GyTAR has a better packet delivery ratio than GSR.

UMB (Urban Multi-hop Broadcast Protocol) [68] is a Broadcast location-based routing protocol adapted to the context of the IVC. UMB has been proposed in the purpose to avoid certain problems such as the reduction of the collisions of packets, the interferences and the problem of the hidden station during the dissemination of messages in multi-hops. UMB is composed of two phases: the first one called directional broadcasting where the source selects a node in the direction of distribution to relaying the data without any information about the topology, and the second distribution (broadcasting) in the intersections, to disseminate the packets in all the directions. The principal advantage of UMB is the multi-hop broadcast reliability in urban canals [69, 70]. However, a fixed receiver installation is required for each intersection. In case of an extended network, the installation needed cost high in term of materials and time.

PBSM (Parameterless Broadcast in Static to Highly Mo bile) [71] is a broadcast routing protocol that uses Connected Dominating Sets (CDS) and neighbour elimination mechanism to eliminate redundant broadcast. This protocol uses two-hop neighbour's information obtained by the exchange of the periodic beacons to construct CDS. PBSM does not require nodes to know about the location and movement of their neighbours and itself. Within the PBSM protocol, each vehicle $V$ maintains two routing tables: neighbours table called $R$ contains all the neighbours that have already received the broadcast packet and NR the others. Each vehicle $V$ broadcasts the packet if the table NR is not empty, after the timer expiration. In the aim to minimize the control packet overhead in data forwarding, another mechanism called CKPBSM [72] was proposed to deliver the packet to the network. Unless, the store and the forward technique used both by PBSM and CKPBSM cost high in term of delay. Therefore, it is unsuitable for safety application in vehicle networks [25].

ROVER (Reliable Geographical Multicast Routing in Vehicular Ad Hoc Networks) [73] is a Geocast routing protocol for VANET. ROVER has some predefined geographi cal regions called Zone of Relevance (ZOR) that is usually specified as a rectangular on the digital map of vehicles. This routing has some similarities with the routing technique used in AODV that consists of distributing only the control messages while the data packets are always unicasted. Nodes broadcast packets to a specific ZOR where packets are being broadcasted to all nodes within the ZOR. When a node wants to forward a packet makes a Zone of Forward (ZOF) and sends the packet. The purpose of ROVER is to deliver the geocast message generated by an application of the source node towards all the vehicles situated in specific ZOR and defined the message as a triple (Application, message, ZOR). This routing suffers from a high control packet overhead [74].

IVG (Inter Vehicular Geocast) [75] is a geocast routing protocol. The aim of IVG is to broadcast an alarm message to all the vehicles being in risk area based on the defer time algorithm in a high way. The vehicles that are at the extremities of the transmission range send the message and so on. This region is defined according to the precise location of the obstacle on the road and all the directions that can be affected. This routing is designed to solve the problems such as the determination of the direction, the location in the space and the dissemination of the information, which are owed to the high mobility of nodes. The purpose of this protocol is to avoid the collisions of packets and to reduce the number of rebroadcast thus the loss of information as well as the overload of the network. The protocol IVG is based on the calculation of "defer Time back off", an interval of the difference of reception time of an answer, which is calcu- 
lated according to the distance between nodes in particular transmission range of the antenna with the aim of minimizing the number of the broadcasted messages. The principal advantages of IVG protocol that reduces the number of hops for a message dissemination using multicast group, reduce the network fragmentations using periodic broadcasts and calculating the time of rebroadcasting according to the speed of vehicles to ameliorate protocol efficiency. However, in IVG protocol vehicles belonging to the risk area are informed by a periodic transmission of beacons, which increase the transmission overhead. In addition, the number of multicast groups increases within congested traffic, which results in more transmission delay [76].

Geocache (Sharing and Exchanging Road Traffic Information using Peer-to-Peer Vehicular Communication) [77] is a geocast routing protocol. The aim of Geocache protocol is the sharing and the exchange of road traffic information between vehicles to enable them to detect and to avoid road congestion. The authors of the paper have designed this protocol to allow vehicles to cooperatively collect and disseminate data in an efficient way. The protocol uses a very effective caching mechanism to reduce the amount of information exchanged in the network between vehicles. Among the advantages of the Geocache protocol is the reduction of the information circulated in the network due to the caching mechanism used. The drawback of routing protocol appears when the congestion factor increases which leads to a long delay of response time.

\section{Discussion and Comparison}

This section provides a comparison between the reviewed routing strategies from different perspectives. Table 1 summarizes the characteristics of representative routing protocols that have either been used or designed specifically for VANETs.

In this table, we present the different categories of routing protocols in VANET networks reviewed in the last section. Moreover, we provide a comparison of these routing protocols on the basis of the following parameters: Routing maintenance, routing type, transmission strategy, forwarding strategy and simulation scenario. Among this scenario, the proactive routing protocol works best in highway scenario and reactive in an urban scenario.

Routing type: Based on the links information used to achieve packet forwarding, the routing protocols fall within two categories of topology-based and location-based routing (geographic or hierarchical).

Transmission strategy: Consists of the mechanism used by the routing to deliver the data packet from a source node to the destination one. It can be either unicast, multicast or broadcast.

Forwarding strategy: Approach allowing messages to reach the destination area. Greedy forwarding, multi Hop or store and forward are the main used approaches.

Routing Maintenance: Describes the way the route to the destination area is found. The routing protocol can be classified into two major categories as reactive and proactive, depending on the route discovery time.

Most of the proposed routing protocols try to find an optimal solution for forwarding data using different techniques of routing with the aim to ensure high throughput, an acceptable level of packet loss and keeping the network overhead under controllable levels [22, 78].

The routing of the Topology-based approach utilizes the link information about the network nodes to forward the data packets. The approach suffers from routing route breaks because of the regular basis changes in the information about links. Despite its good property of providing low latency for real-time applications, the maintenance of unused paths occupies a significant part of the bandwidth in a highly mobile network. Since they provide a very low communication throughput, the proactive algorithms are not suitable in VANETs. Unlike to proactive routing protocols, in an on-demand routing protocol, the routing traffic floods the network only when a route is required. Thus, the nodes in the network exchange no regular routing updates. However, the delay generated by the route discovery process in finding a route is an issue for vehicular communication especially real-time applications.

In addition, the scalability issue is another concern of the approach since the reactive routing protocols are still considered in small-scale networks with a path of a few hops. AODV and DSR are designed for general purpose mobile ad hoc networks and do not maintain routes unless they are needed. Hence, they can reduce overhead, especially in scenarios with a small number of network flows. Thus, certain modification of the ad hoc routing protocols that have been developed to deal with highly dynamic mobility of nodes in the context of VANETs or new routing protocols needed to be developed since many of them do not apply well to VANETs. The advantages' reactive protocols are that they offer greater adaptability to the topological changes of highly mobile ad hoc network such as VANET. However, these types use a flooding method for route discovery that initiates more overhead and suffers from the initial route discovery method. Thus, they become inadequate for security applications.

The hybrid routing protocols are designed to reduce the control overhead of proactive routing protocols and decrease the initial route discovery delay in reactive routing protocols. The routing has the advantages of distance vector and link-state routing protocols and merges them into a new protocol. However, disadvantages of the hybrid routing are flooding useless and rising overhead costs. These routing protocols are mainly introduced for networks where the nodes are not highly mobile. 


\begin{tabular}{|c|c|c|c|c|c|c|c|c|}
\hline 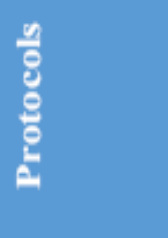 & 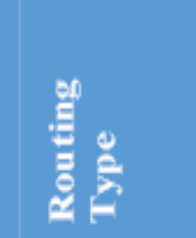 & 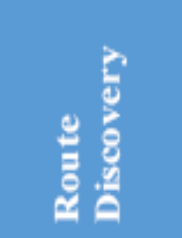 & 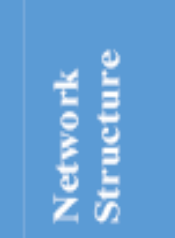 & 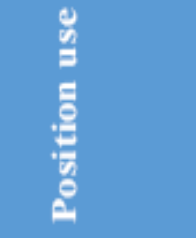 & 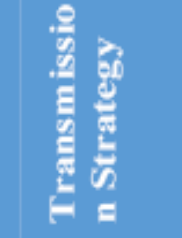 & of $\frac{E}{E}$ & 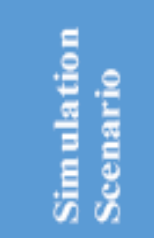 & 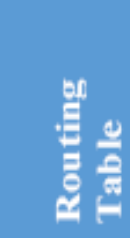 \\
\hline DSDV & $\begin{array}{l}\text { Topology- } \\
\text { based }\end{array}$ & Proactive & Flat & - & Unicast & $\begin{array}{l}\text { Distance } \\
\text { Victor }\end{array}$ & - & No \\
\hline OLSR & $\begin{array}{l}\text { Topology- } \\
\text { based }\end{array}$ & Proactive & Flat & - & Unicast & Link states & Urban & Yes \\
\hline FSR & $\begin{array}{l}\text { Topology- } \\
\text { based }\end{array}$ & Proactive & Flat & - & Unicast & Link states & - & Yes \\
\hline DSR & $\begin{array}{l}\text { Topology- } \\
\text { based }\end{array}$ & Reactive & Flat & - & Unicast & $\begin{array}{l}\text { Source } \\
\text { Flooding }\end{array}$ & - & No \\
\hline AODV & $\begin{array}{l}\text { Topology- } \\
\text { based }\end{array}$ & Reactive & Flat & - & $\begin{array}{l}\text { Unicast / } \\
\text { Multicast }\end{array}$ & $\begin{array}{l}\text { Distance } \\
\text { Victor }\end{array}$ & Urban & No \\
\hline TORA & $\begin{array}{l}\text { Topology- } \\
\text { based }\end{array}$ & Reactive & Flat & - & Unicast & $\begin{array}{l}\text { Distance } \\
\text { Victor }\end{array}$ & - & Yes \\
\hline ZRP & $\begin{array}{l}\text { Topology- } \\
\text { based }\end{array}$ & Hybrid & Flat & $\begin{array}{l}\text { Cluster } \\
\text { Formation }\end{array}$ & Unicast & Link states & Urban & Yes \\
\hline$H A R P$ & $\begin{array}{l}\text { Topology- } \\
\text { based }\end{array}$ & Hybrid & Flat & $\begin{array}{l}\text { Cluster } \\
\text { Formation }\end{array}$ & Multicast & Link states & - & Yes \\
\hline HSR & $\begin{array}{l}\text { Location- } \\
\text { based }\end{array}$ & Proactive & Hierarchic & $\begin{array}{l}\text { Cluster } \\
\text { Formation }\end{array}$ & Unicast & Link states & - & Yes \\
\hline CBRP & $\begin{array}{l}\text { Location- } \\
\text { based }\end{array}$ & Hybrid & Hierarchic & $\begin{array}{l}\text { Cluster } \\
\text { Formation }\end{array}$ & Unicast & Link states & - & Yes \\
\hline CBDRP & $\begin{array}{l}\text { Location- } \\
\text { based }\end{array}$ & Reactive & Hierarchic & $\begin{array}{l}\text { Cluster } \\
\text { Formation }\end{array}$ & Multicast & $\begin{array}{l}\text { Store \& } \\
\text { Forward }\end{array}$ & Map & Yes \\
\hline GSR & Geographic & $\begin{array}{l}\text { Proactive } \\
\text { Non-DTN }\end{array}$ & Flat & $\begin{array}{l}\text { Packet } \\
\text { Forwarding }\end{array}$ & Unicast & Greedy & $\begin{array}{l}\text { Real city } \\
\text { (Map) }\end{array}$ & No \\
\hline GPSR & Geographic & $\begin{array}{l}\text { Reactive } \\
\text { Non-DTN }\end{array}$ & Planar & $\begin{array}{c}\text { Greedy } \\
\text { Forwarding }\end{array}$ & Unicast & Greedy & Urban & No \\
\hline GPCR & Geographic & $\begin{array}{l}\text { Reactive } \\
\text { Non-DTN }\end{array}$ & Planar & $\begin{array}{l}\text { Greedy } \\
\text { Forwarding }\end{array}$ & Unicast & Greedy & $\begin{array}{l}\text { Real city } \\
\text { (Map) }\end{array}$ & No \\
\hline A-STAR & Geographic & $\begin{array}{l}\text { Reactive } \\
\text { Non-DTN }\end{array}$ & Flat & $\begin{array}{l}\text { Packet } \\
\text { Forwarding }\end{array}$ & Unicast & Greedy & $\begin{array}{l}\text { Grid city } \\
\text { model }\end{array}$ & No \\
\hline GyTAR & Geographic & $\begin{array}{l}\text { Reactive } \\
\text { Non-DTN }\end{array}$ & Flat & $\begin{array}{l}\text { Greedy } \\
\text { Forwarding }\end{array}$ & Unicast & Greedy & Urban & No \\
\hline UMB & Geographic & $\begin{array}{l}\text { Reactive } \\
\text { Non-DTN }\end{array}$ & Flat & $\begin{array}{l}\text { Packet } \\
\text { Forwarding }\end{array}$ & Broadcast & $\begin{array}{l}\text { Directed } \\
\text { Flooding }\end{array}$ & Urban & No \\
\hline PBSM & Geographic & $\begin{array}{l}\text { Reactive } \\
\text { Non-DTN }\end{array}$ & Flat & $\begin{array}{l}\text { Packet } \\
\text { Forwarding }\end{array}$ & Broadcast & Flooding & Urban & No \\
\hline IVG & Geographic & $\begin{array}{l}\text { Reactive } \\
\text { Non-DTN }\end{array}$ & Flat & $\begin{array}{l}\text { Greedy } \\
\text { Forwarding }\end{array}$ & Geocast & Flooding & Highway & No \\
\hline ROVER & Geographic & $\begin{array}{l}\text { Reactive } \\
\text { Non-DTN }\end{array}$ & Flat & Multi Hop & Geocast & Flooding & Urban & No \\
\hline Geocache & Geographic & $\begin{array}{l}\text { Reactive } \\
\text { Non-DTN }\end{array}$ & Flat & $\begin{array}{l}\text { Greedy } \\
\text { Forwarding }\end{array}$ & Geocast & Greedy & $\begin{array}{l}\text { Highway } \\
\text { \& Urban }\end{array}$ & No \\
\hline
\end{tabular}

Table 1. Summary of VANET routing protocols 
It has been shown that routing approaches using position information can adapt to the high mobility of nodes found in highway situations [8]. Some of the studies have compared the performance of topology-based routing such as AODV and DSR against geographic routing strategies in urban as well as highway traffic scenarios [52, 54]. Therefore, geographic routing has been identified as a well promising routing in context of the VANETs. With the cluster-based techniques, the role of scalability for large networks such as VANETs can be provided. However, because of the geographical constraints of VANETs and the highly dynamic mobility of nodes in the network, the cluster-based routing strategies may involve during the process of cluster formation and the maintenance one a significant delay and communications overhead.

Location-based routing uses geographical location information to generate an efficient route through the network. Geocast routing is proposed to avoid packet collisions and reduce the number of rebroadcasts. Routing strategies that use geographical location information obtained from street maps, traffic models or even more prevalent navigational systems on-board the vehicles make sense. The most of unicast greedy routing protocols use a position-based to provide vehicle-to-vehicle communication. In the greedy forwarding strategy, direct communications between nodes may not exist because of obstacles such as buildings and trees. Thus, the strategy is generally restricted in city scenarios. Consequently, the routing faces great challenges in a built-up city environment. Some studies utilize the digital map $[64,66]$ to deal with these challenges. The greedy forwarding as a data delivering technique is employed the most of the proposed routing protocols for VANETs. The technique aims to reduce the number of hops and reduce the delay of data delivery. The greedy forwarding as a data delivering technique is employed by most of the proposed routing protocols for VANETs. The technique aims to reduce the number of hops and reduce the delay of the data delivery. The unicast is a useful mode of communication in VANETs. However many applications will require dissemination of messages to many different nodes in the network. Over the routing strategy reviewed, the geocast routing was improved by many researchers to become one of the preferred solutions ones. Reactive-based routing protocols are considered as the most used method in VANETs. Routing using this method is adequate to scenarios in highly dynamic networks where vehicles are frequently leaving or joining the network.

The intents of VANET are to reach an efficient routing protocol that gratifies the following measures: reduce the end-to-end delay, decrease the consumption of bandwidth and avoid collisions in the circumstances of the high mobility of nodes and changes topologies. Routing in VANET has problems of instability of the roads caused by the high mobility of nodes and communication problem in environments where there are obstacles, is the case in an urban environment. In general, the routing is categorized in city and highway routing categories. The city environment is characterized by a large number of road options, constrained vehicular speed, vehicle density and the varying speed of vehicles as well as obstacles including tall buildings on roadsides and the number of traffic lights. Likewise, the highway environment is characterized by sparse network, very high vehicular speed, road with a number of lanes and one-way traffic $[79,80]$.

The geocast routing aims to guarantee the sending of prised data consistently and timely with the lowest cost. It is essential to improve the value of stability and taking into consideration the change in the topology and node mobility during the interval of time to avoid the interference of packets. While vehicles are moving at high speed, the topology is constantly changing. The highly dynamic topology leads to intermittent connectivity since the link between two vehicles can speedily disappear while nodes are transferring data. The delinquent is further aggravated by node density where frequently travelled roads have more cars than non-frequently moved roads. Furthermore, nonrush hours effects in disparate node density, hence disconnectivity [81]. A robust routing protocol needs to recognize frequent disconnectivity and provides an alternative link quickly to ensure uninterrupted communication. A vigorous routing algorithm requests to diagnose the frequent disconnectivity and offers a substitute link quickly to guarantee uninterrupted communication.

In summary, we conclude that the geocast routing is more promising in the context of vehicular communication than any other routing strategy reviewed in the paper, due to the constraints on mobility, the vehicular density, and high speeds of the nodes in the network. However, the performance evaluation of a routing protocol in VANETs depends heavily on the mobility model and the propagation model.

\section{Issues and Challenges}

There are several issues and prerequisite that should be considered when designing VANETs routing. This diversity leads to a number of challenges $[82,83]$ that need to be resolved in order to deploy vehicular networks. This section addresses the main research challenges to be considered for routing algorithms on VANETs. These include high speed and frequent topology changes, hidden and exposed node problems, security and trust, quality of service and simulation issues [84]. Scalability and interoperability are two important issues that should be satisfied, and the employed algorithms should be scalable to numerous vehicles and interoperable with different wireless technologies. The following subsections discuss a number of these challenges.

\subsection{High Speed and Frequent Topology Changes}

In vehicular networks, the vehicles move very fast on road. This causes frequent changes in the topology of the network. However, due to road geometry, the directions of the vehicles can be predicted to a certain extent. This issue should be handled carefully by the MAC protocol [85]. For example, two nodes can communicate if they 
are in the transmission range of each other. If one node moves very fast, it will be out of the other nodes' range before completing the transmission. Due to high node density and high speed, the system performance can degrade dramatically. Another example is when vehicles move with speed of $120 \mathrm{~km}$ or even $150 \mathrm{~km}$ per hour, the probability of having frequent link disconnections increases. Therefore, the MAC protocol should address mobility issues and estimate accurately the condition of the highly dynamic channel [86].

\subsection{Hidden and Exposed Node Problems}

In ad hoc routing algorithms, the hidden node problem is conceded as a traditional one. The problem of the hidden node occurs when a node is visible from an access point (AP), but not from other nodes communicating with that AP. This leads to difficulties in medium access control (MAC) sublayer. In VANETs, due to the high-speed mobility in the network, the hidden node problem is expected to happen more frequently [87]. These problems are known to degrade the throughput of wireless networks due to collisions, and results in poor performance by wasting valuable transmission. Extensive research has been conducted to solve these problems, such as Carrier Sense Multiple Access with Collision Avoidance (CSMA/CA) [88].

\subsection{Scalability}

Vehicular networks can be considered a typical example where scalability is required. In a communication system that has very high mobility such as in VANETs, changes of network size should be handled carefully. It is normal to have a situation where vehicle density is near the average. However, the vehicle density can suddenly grow significantly and becomes very large in a road segment. Operability in both sparse and high node density situations is very important for routing protocols. An effective routing algorithm should be adaptive to various network information load and vehicle density [89]. In this context, scalability can be defined as the ability to accept an increase in the number of nodes in the network without suffering a noticeable decrement in performance or a complexity increment [90]. Several studies on performance evaluations show that some protocols do not work properly in a high node density especially in a highly dense network topology [91, 92]. In such cases, the network may not provide the desired performance unless the routing protocol is designed to address this issue.

\subsection{Security and trust}

The security of communication in VANETS is a major challenge, having a great impact on future deployment and application in such networks. Indeed, security and privacy are major issues in the development and should not be compromised by ease-of-use of service discovery protocols [93]. The primary uses identified for VANETs are safety-related messages, transportation efficiency, and entertainment content [94]. The Vehicle Safety Communications-Applications consortium identified some potentially life-saving warnings, including emergency electronic brake light, pre-crash sensing, cooperative forward collision warning, left turn assistant, lane-change warning, traffic signal violation warning, curve speed warning, and stop sign movement assistant [53]. For security and safety reasons, messages must be authenticated to ensure that a legitimate member of the VANET sent the message [95]. This is especially critical for safety-related messages. When a user sends out erroneous messages whether intentionally or unintentionally, other members of the VANET should ignore those messages to protect their safety.

\subsection{Quality of service}

Different applications of VANET are expected to require different Quality of Service (QoS) such as node position, the distance between nodes, link delay and reliability of links in the aim to contribute to the stability of routes [96]. So, QoS is another important issue to be concerned by routing algorithms in VANETs. However, this task is difficult to be achieved especially in a highly dynamic network such as VANET. A QoS routing protocol attempts to provide guarantees about the level of performance provided [97]. However, QoS metrics for VANET should be well-defined $[83,98]$.

\subsection{Performance metrics}

Because of the specific condition addressing by the different routing algorithms, there is no standard methodology to validate their performance. Different performance metrics can be used to evaluate the VANET routing, such as packet loss, packet error, packet delivery ratios and end-to-end delay [99]. However, some approaches propose other performance metrics that can better evaluate specific application scenarios, such as in [100]. The cost and complexity of implementing routing in VANET and applications in large test-bed systems forces such an implementation to be within a simulation environment [101]. Despite the number of simulators different in their implementation, some parameters cannot directly be translated over. Since the scalability is a huge challenge in VANET, it is impossible to simulate the full stack of very large networks [102]. In addition, mobility model and propagation model are major challenges that should be addressed in the context of VANET simulation. These model present simulation settings used for protocol evaluation. The mobility models should address sufficient levels of complexity to simulate realistic traffic scenarios and realistic driving behavior [103]. In general, mobility simulators are commonly used in the evaluation process because of the limitation of mobility traces that can be either obtained from a close-to-reality traffic simulator or from actual traces. Yet, specifications about these simulator parameters are mostly non-standard. However, the credibility and feasibility of simulation systems require reliable and standardized simulation parameters so that verification techniques can be applied [104].

\section{Conclusions and Future Research Directions}

Nowadays, different new applications are enabled by ve- 
hicular communication network. However, as those applications have an impact in road traffic safety, strong routing requirements must be achieved. New mechanisms have to be developed and improved to deal with the inherent features of these networks. In this paper, we have presented an overview of the current routing issues over VANETs, focusing on road safety communications. We have introduced a common underlying model for this kind of network, along with its main settings. We have also reviewed several routing approaches that can be performed in the context of VANET networks. Moreover, we have identified the routing requirements that are present on each VANET setting. Finally, we have described and analyzed the main proposed algorithms to achieve the routing goals.

VANET routing is an emerging area in which several future research issues can be pointed out. Although many protocols have been proposed, some concerns still have to be addressed such as the security and the QoS problems. In addition, as different VANET protocols and applications are based on several features and architectures, a common evaluation method is required to compare different routing protocols. Simulation results are generally provided to evaluate the performance of the current proposals. Unless, A common scenario to evaluate alternatives still to be a concern.

Geocast Routing still has various challenges that have not been inspected yet. These challenges offer pronounced openings for the innovative investigators, as VANET is a huge technology. In summary, the open issue in VANET routing is then whether there is any standard method for evaluating the performances of these protocols. We are currently working on routing optimization for VANETs. As future work, we will design a new optimized geocast routing protocol and we will propose an optimal approach to send the packets of a message from the source node to all the nodes within a specified forwarding area based on the directed flooding. We aim to reduce message overhead and network congestion. Therefore, we will discuss the real-life data-based verification systems of our results and as well as other performance metrics.

\section{References}

[1] Nadeem, T., Shankar, P., Iftode, L. (2006). A comparative study of data dissemination models for VANETs. In: 2006 Third Annual International Conference on Mobile and Ubiquitous Systems: Networking \& Services (ICMUS'06), 1-10. IEEE, July 2006.

[2] Contreras-Castillo, J., Zeadally, S., \& Guerrero-lbañez, J. A. (2017). Internet of vehicles: architecture, protocols, and security. IEEE Internet of Things Journal, 5 (5) 3701 3709.

[3] Kaiwartya, O., Abdullah, A. H., Cao, Y., Altameem, A., Prasad, M., Lin, C. T., Liu, X. (2016). Internet of vehicles: Motivation, layered architecture, network model, challenges, and future aspects. IEEE Access, 4 (18) 5356-5373.

[4] Jiang, D., Delgrossi, L. (2008). IEEE 802.11 p: Towards an international standard for wireless access in vehicular environments. In: VTC Spring 2008-IEEE Vehicular Technology Conference, p. 2036- 2040. IEEE, May 2008.

[5] Lin, Y. W., Chen, Y. S., Lee, S. L. (2010). Routing protocols in vehicular ad hoc networks: A survey and future perspectives. Information Science and Engineering Journal, 26 (3) 913-932.

[6] Hossain, E., Chow, G., Leung, V. C., McLeod, R. D., Miši, J., Wong, V. W., Yang, O. (2010). Vehicular telematics over heterogeneous wireless networks: A survey. Computer Communications, 33 (7) 775-793.

[7] Li, F., Wang, Y. (2007). Routing in vehicular ad hoc networks: A survey. IEEE Vehicular technology magazine, 2 (2) $12-22$.

[8] Lee, K. C., Lee, U., Gerla, M. (2010). Survey of routing protocols in vehicular ad hoc networks. In: Advances in vehicular ad-hoc networks: Developments and challenges, p 149-170. IGI Global, 2010.

[9] Hartenstein, H., Laberteaux, L. P. (2008). A tutorial survey on vehicular ad hoc networks. IEEE Communications magazine, 46 (6) 64-171.

[10] Paul, B., Ibrahim, M., Bikas, Md. A. (2011). VANET Routing Protocols: Pros and Cons'. International Journal of Computer Applications, 20 (3), 28-34.

[11] Chen, W., Guha, R. K., Kwon, T. J., Lee, J., \& Hsu, Y. Y. (2011). A survey and challenges in routing and data dissemination in vehicular ad hoc networks. Wireless Communications and Mobile Computing 11 (7) 787-795.

[12] Al-Sultan, S., Al-Doori, M. M., Al-Bayatti, A. H., Zedan, H. (2014). A comprehensive survey on vehicular ad hoc network. Journal of network and computer applications 37 (2014) 380-392.

[13] Karagiannis, G., Altintas, O., Ekici, E., Heijenk, G., Jarupan, B., Lin, K., Weil, T. (2011). Vehicular networking: A survey and tutorial on requirements, architectures, challenges, standards and solutions. IEEE communications surveys \& tutorials 13 (4) 584-616.

[14] Euchi, J. (2017). The vehicle routing problem with private fleet and multiple common carriers: Solution with hybrid metaheuristic algorithm. Vehicular Communications 9 (2017) 97-108.

[15] Oubbati, O. S., Lakas, A., Zhou, F., Güne_, M., Lagraa, N., Yagoubi, M. B. (2017). Intelligent UAVassisted routing protocol for urban VANETs. Computer communications 107 (2017) 93-111.

[16] Marzak, B., Toumi, H., El Guemmat, K., Benlahmar, A., Talea, M. (2016). A survey on routing protocols for vehicular ad-hoc networks. Indian Journal of Science and Technology 9 (S1) 1-20. 
[17] Maidorawa, A., Bakar, K. A. (2014). An Enhanced Connectivity Aware Routing Protocol for Vehicular Ad hoc Networks. Research Journal of Applied Sciences, Engineering and Technology 7 (14) 2935-2945.

[18] Cheng, J., Cheng, J., Zhou, M., Liu, F., Gao, S., Liu, C. (2015). Routing in internet of vehicles: A review. IEEE Transactions on Intelligent Transportation Systems 16 (5) 2339-2352.

[19] Lin, Y. W., Chen, Y. S., Lee, S. L. (2010). Routing protocols in vehicular ad hoc networks: A survey and future perspectives. Information Science and Engineering Journal 26 (3) 913-932.

[20] Dua, A., Kumar, N., Bawa, S. (2014). A systematic review on routing protocols for vehicular ad hoc networks. Vehicular Communications 1 (1) 33-52.

[21] Paul, B., Islam, M. J. (2012). Survey over VANET routing protocols for vehicle to vehicle communication. IOSR Journal of Computer Engineering (IOSRJCE) 7 (5) 1-9.

[22] Sharef, B. T., Alsaqour, R. A., Ismail, M. (2014). Vehicular communication ad hoc routing protocols: A survey. Journal of network and computer applications 40 (2014) 363-396.

[23] Gupta, R., Patel, P. (2016). A survey on vehicular ad hoc networks. International Journal of Scientific Research in Science, Engineering and Technology (IJSRSET) 15 (4) $34-42$.

[24] Senouci, O., Aliouat, Z., Harous, S. (2019). A review of routing protocols in internet of vehicles and their challenges. Sensor Review 39 (1) 58-70.

[25] Kakarla, J., Sathya, S. S., Laxmi, B. G. (2011, August). A Survey on Routing Protocols and its Issues in VANET. International Journal of Computer Applications 28 (4) 38-44.

[26] Bharadwaj, P. S., Rashmi, S., Shylaja, B. S. (2011,). Performance evaluation of MANET based routing protocols for VANETs in Urban Scenarios. In: International Conference on Network and Electronics Engineering (IPCSIT), Vol. 11 p. 164-169. Singapore, September 2011.

[27] Farooq, W., Khan, M. A., Rehman, S., Saqib, N. A. (2015). A survey of multicast routing protocols for vehicular ad hoc networks. International Journal of Distributed Sensor Networks 11 (8) 1-12.

[28] Vodopivec, S., Bešter, J., Kos, A. (2012). A survey on clustering algorithms for vehicular ad-hoc networks. In: 2012 35th International Conference on Telecommunications and Signal Processing (TSP), p. 52-56. IEEE, July 2012.

[29] Govindaswamy, V., Blackstone, W. L., Balasekara, G. (2011). Survey of recent position based routing mobile ad-hoc network protocols. In: 2011 UkSim $13^{\text {th }}$ International Conference on Computer Modelling and Simula- tion, p, 467-471. IEEE, March 2011.

[30] Bernsen, J., Manivannan, D. (2009). Unicast routing protocols for vehicular ad hoc networks: A critical comparison and classification. Elsevier Journal of Pervasive and Mobile computing 5(1) 1-18.

[31] Singh, P. (2014). Comparative study between unicast and Multicast Routing Protocols in different data rates using vanet. In: 2014 International Conference on Issues and Challenges in Intelligent Computing Techniques (ICICT), p. 278-284. IEEE, February 2014.

[32] Allal, S., Boudjit, S. (2013). Geocast Routing Protocols for VANETs: Survey and Geometry-Driven Scheme Proposal. Journal of Internet Services and Information Security $3(1 / 2)$ 20-36.

[33] Liu, G., Lee, B. S., Seet, B. C., Foh, C. H., Wong, K. J., Lee, K. K. (2004). A routing strategy for metropolis vehicular communications. In: International Conference on Information Networking (ICOIN), p. 134-143. Springer, Berlin, Heidelberg, February 2004.

[34] Abdulhamid, H., Tepe, K. E., Abdel-Raheem, E. (2007). Performance of DSRC systems using conventional channel estimation at high velocities. AEU-International Journal of Electronics and Communications 61 (8) 556-561.

[35] Car-to-Car Communication Consortium (2007). C2CCC Manifesto. Version 1.1, 28th August 2007. http:// www.car-to-car.org. Available: http://elib.dlr.de/48380/1/ C2C-CC_manifesto_v1.1.pdf. [Accessed 0906 2019].

[36] Xu, Q., Mak, T., Ko, J., Sengupta, R. (2004). Vehicle-to-vehicle safety messaging in DSRC. In: Proc.of the 1st ACM international workshop on Vehicular ad hoc networks, p.19-28. ACM, October 2004.

[37] US Federal Communications Commission. (2003). FCC Report and Order 03-324: Amendment of the Commission's Rules Regarding Dedicated Short Range Communication Services in the 5.850-5.925 GHz Band. 2003.

[38] Festag, A., Hess, S. (2009). ETSI technical committee ITS: news from European standardization for intelligent transport systems (ITS)-[global communications newsletter]. IEEE Communications Magazine, 47 (6) 14.

[39] IEEE Trial-Use Standard for Wireless Access in Vehicular Environments (WAVE). Resource Manager, IEEE Std 1609.1-2006, 2006.

[40] IEEE Standard 1609.2: IEEE Trial-Use Standard for Wireless Access in Vehicular Environments (WAVE), Security Services for Applications and Management Messages, 2006.

[41] IEEE Trial-Use Standard for Wireless Access in Vehicular Environments (WAVE). Networking Services, IEEE Std 1609.3-2007, 2007.

[42] IEEE Std 1609: IEEE Trial-Use Standard for Wire- 
less Access in Vehicular Environments (WAVE), Multichannel Operation, April 2006.

[43] Draft Standard for Information Technology-Telecommunications and information exchange between systemsLocal and metropolitan area networks-Specific requirements Part 11: Wireless LAN Medium Access Control (MAC) and Physical Layer (PHY) specifications Amendment 7: Wireless Access in Vehicular Environments, IEEE Unapproved Draft Std P802.11p/D9.0, July 2009.

[44] IEEE Standard for Information technology-Telecommunications and information exchange between systemsLocal and metropolitan area networks-Specific requirements-Part 11: Wireless LAN Medium Access Control (MAC) and Physical Layer (PHY) Specifications, IEEE Std 802.11-2007. 2007.

[45] Liang, W., Li, Z., Zhang, H., Wang, S., \& Bie, R. (2015). Vehicular ad hoc networks: architectures, research issues, methodologies, challenges, and trends. International Journal of Distributed Sensor Networks 11 (8) 745303.

[46] Qayyum, A., Viennot, L., \& Laouiti, A. (2002). Multipoint relaying for flooding broadcast messages in mobile wireless networks. In: Proc. of the 35th annual Hawaii international conference on system sciences, Hawai, USA, pages 3866-3875. IEEE, January 2002.

[47] Clausen, T., \& Jacquet, P. (2003). Optimized link state routing protocol (OLSR) (No. RFC 3626). 2003.

[48] Perkins, C. E., \& Bhagwat, P. (1994, October). Highly dynamic destination-sequenced distance-vector routing (DSDV) for mobile computers. In ACM SIGCOMM computer communication review 24 (4) 234-244.

[49] Pei, G., Gerla, M., \& Chen, T. W. (2000). Fisheye state routing: A routing scheme for ad hoc wireless networks. In: 2000 IEEE International Conference on Communications (ICC' 2000). Global Convergence Through Communications, New Orleans, LA, Conference Record, Vol. 1, pages 70-74. IEEE, June 2000.

[50] Perkins, C., Belding-Royer, E., \& Das, S. (2003). Ad hoc on-demand distance vector (AODV) routing. Request For Comments, (No. RFC 3561). 2003.

[51] Wang, S. Y., Lin, C. C., Hwang, Y. W., Tao, K. C., \& Chou, C. L. (2005). A practical routing protocol for vehicle-formed mobile ad hoc networks on the roads. In: Proc. of the $8^{\text {th }}$ IEEE international conference on intelligent transportation systems, pages 161-165. IEEE, September 2005.

[52] Johnson, D., Hu, Y. C., \& Maltz, D. (2007). The dynamic source routing protocol (DSR) for mobile ad hoc networks for IPv4 (No. RFC 4728). 2007.

[53] Namboodiri, V., Agarwal, M., \& Gao, L. (2004). A study on the feasibility of mobile gateways for vehicular ad-hoc networks. In: Proc. of the $1^{\text {st }}$ ACM international workshop on Vehicular ad hoc networks, pages 66-75. ACM, October 2004.
[54] Park, V. (2001). Temporally-ordered routing algorithm (TORA) version 1 functional specification. IETF Internet Draft. 2001. draft-ietf-manet-tora-spec-04.txt.

[55] Haas, Z. J., Pearlman, M. R., \& Samar, P. (2002). The zone routing protocol (ZRP) for ad hoc networks. IETF Internet Draft. 2002. https://tools.ietf.org/html/draftietfmanet-zone-zrp-04.

[56] Nikaein, N., Bonnet, C., \& Nikaein, N. (2001). Harphybrid ad hoc routing protocol. In: Proc. of international symposium on telecommunications (IST), p 56-67. September 2001.

[57] Liu, C., \& Kaiser, J. (2005). Survey of mobile ad hoc network routing protocols. University of Ulm, Germany, pages 1-36. October 2005.

[58] Nikaein, N., Labiod, H., \& Bonnet, C. (2000). DDR: distributed dynamic routing algorithm for mobile ad hoc networks. In: Proc. of the $1^{\text {st }}$ ACM international symposium on Mobile ad hoc networking \& computing, pages 19-27. IEEE Press, November 2000.

[59] Joa-Ng, M., \& Lu, I. T. (1999). A peer-to-peer zonebased two-level link state routing for mobile ad hoc networks. IEEE Journal on selected areas in communications 17 (8) 1415-1425.

[60] Jiang, M. (1999). Cluster based routing protocol (CBRP). IETF Internet-draft. draft-ietfmanet-cbrpspec01.txt, August 1999.

[61] Song, T., Xia, W., Song, T., \& Shen, L. (2010). A cluster-based directional routing protocol in VANET. In: 2010 IEEE 12th International Conference on Communication Technology, pages 1172-1175. IEEE, November 2010.

[62] Karp, B., \& Kung, H. T. (2000). GPSR: Greedy perimeter stateless routing for wireless networks. In: Proc. of the 6th annual international conference on Mobile computing and networking, Boston, MA, USA, pages 243-254. ACM, August 2000.

[63] Broch, J., Maltz, D. A., Johnson, D. B., Hu, Y. C., \& Jetcheva, J. G. (1998). A performance comparison of multihop wireless ad hoc network routing protocols. In: Proc. of the Fourth Annual ACM/IEEE International Conference on Mobile Computing and Networking (MobiCom' 98), Dallas, Texas, USA, pages 85-97. ACM, October 1998.

[64] Lochert, C., Mauve, M., Fübler, H., \& Hartenstein, H. (2005). Geographic routing in city scenarios. ACM SIGMOBILE mobile computing and communications review 9 (1) 69-72.

[65] Lochert, C., Hartenstein, H., Tian, J., Fussler, H., Hermann, D., \& Mauve, M. (2003). A routing strategy for vehicular ad hoc networks in city environments. In: Proc. Of the IEEE IV2003 Intelligent Vehicles Symposium, pages 156-161. IEEE, June 2003.

[66] Seet, B. C., Liu, G., Lee, B. S., Foh, C. H., Wong, K. J., \& Lee, K. K. (2004). A-STAR: A mobile ad hoc routing strategy for metropolis vehicular communications. In 
ternational Conference on Research in Networking, pages 989-999. Springer, Berlin, Heidelberg, May 2004.

[67] Jerbi, M., Meraihi, R., Senouci, S. M., \& GhamriDoudane, Y. (2006). GyTAR: improved greedy traffic aware routing protocol for vehicular ad hoc networks in city environments. In: 3rd ACM International Workshop on Vehicular Ad hoc Networks, Los Angeles, USA, pages 8889. September 2006.

[68] Korkmaz, G., Ekici, E., Özgüner, F., \& Özgüner, Ü. (2004). Urban multi-hop broadcast protocol for inter-vehicle communication systems. In: Proc. of the 1st ACM international workshop on Vehicular ad hoc networks, pages 76-85. ACM, October 2004.

[69] Korkmaz, G., Ekici, E., \& Ozguner, F. (2006). An efficient fully ad-hoc multi-hop broadcast protocol for inter-vehicular communication systems. In: 2006 IEEE international conference on communications, Vol. 1, pages 423-428. IEEE, June 2006.

[70] Wu, H., Fujimoto, R., Guensler, R., \& Hunter, M. (2004). MDDV: a mobility-centric data dissemination algorithm for vehicular networks. In: Proc. of the 1st ACM international workshop on Vehicular ad hoc networks, pages 47-56. ACM, October 2004.

[71] Ros, F. J., Ruiz, P. M., \& Stojmenovic, I. (2009). Reliable and efficient broadcasting in vehicular ad hoc networks. In: VTC Spring 2009-IEEE 69th Vehicular Technology Conference, pages 1-5. IEEE, April 2009.

[72] Sabahi, F. (2011). The security of vehicular adhoc networks. In: 2011 Third International Conference on Computational Intelligence, Communication Systems and Networks, pages 338-342. IEEE, July 2011.

[73] Kihl, M., Sichitiu, M., Ekeroth, T., \& Rozenberg, M. (2007). Reliable geographical multicast routing in vehicular ad-hoc networks. In: International Conference on Wired/ Wireless Internet Communications: WWIC, LNCS, 4517, pages 315-325. Springer, Berlin, Heidelberg, May 2007.

[74] Karimi, R., Ithnin, N., Razak, S. A., \& Najafzadeh, S. (2011). Non DTN geographic routing protocols for vehicular ad hoc networks. International Journal of Computer Science Issues (IJCSI) 8 (5) 86.

[75] Benslimane, A., \& Bachir, A. (2003). Inter-vehicle geocast protocol supporting non-equipped GPS vehicles. In: International Conference on Ad-Hoc Networks and Wireless, pages 281-286. Springer, Berlin, Heidelberg, October 2003.

[76] Bachir, A., \& Benslimane, A. (2003,). A multicast protocol in ad hoc networks inter-vehicle geocast. In: The 57th IEEE Semiannual Vehicular Technology Conference. VTC 2003-Spring. Vol. 4, pages 2456-2460. IEEE, April 2003.

[77] Lakas, A., \& Shaqfa, M. (2011). Geocache: sharing and exchanging road traffic information using peer-to-peer vehicular communication. In: 2011 IEEE $73^{\text {rd }}$ Vehicular
Technology Conference (VTC Spring), San Francisco, CA, pages 1-7. IEEE, May 2011.

[78] Fonseca, A., \& Vazão, T. (2013). Applicability of position-based routing for VANET in highways and urban environment. Journal of Network and Computer Applications 36 (3) 961-973.

[79] Schoch, E., Kargl, F., Weber, M., \& Leinmuller, T. (2008). Communication patterns in VANETs. IEEE Communications Magazine 46 (11) 119-125.

[80] Wang, Z., Tameh, E. K., \& Nix, A. R. (2008). Joint shadowing process in urban peer-to-peer radio channels. IEEE Transactions on Vehicular Technology 57 (1) 5264.

[81] Kaiwartya, O., \& Kumar, S. (2014). Geocast routing: Recent advances and future challenges in vehicular adhoc networks. In: 2014 International Conference on Signal Processing and Integrated Networks (SPIN), pages 291296. IEEE, February 2014.

[82] Zeadally, S., Hunt, R., Chen, Y. S., Irwin, A., \& Hassan, A. (2012). Vehicular ad hoc networks (VANETS): status, results, and challenges. Telecommunication Systems 50 (4) 217-241.

[83] Lu, N., Cheng, N., Zhang, N., Shen, X., \& Mark, J. W. (2014). Connected vehicles: Solutions and challenges. IEEE internet of things journal 1 (4) 289-299.

[84] Kabir, M. H. (2013). Research issues on vehicular ad hoc network. International Journal of Engineering Trends and Technology (IJETT) 6 (4) 174-179.

[85] Cunha, F., Villas, L., Boukerche, A., Maia, G., Viana, A., Mini, R. A., \& Loureiro, A. A. (2016). Data communication in VANETs: Protocols, applications and challenges. Ad Hoc Networks 44 (2016) 90-103.

[86] Eiza, M. H., Owens, T., \& Ni, Q. (2015). Secure and robust multi-constrained QoS aware routing algorithm for VANETs. IEEE Transactions on Dependable and Secure Computing 13 (1) 32-45.

[87] Jakubiak, J., \& Koucheryavy, Y. (2008). State of the art and research challenges for VANETs. In: 2008 5th IEEE Consumer Communications and Networking Conference, pages 912-916. IEEE, January 2008.

[88] Wang, L., Wu, K., \& Hamdi, M. (2012). Combating hidden and exposed terminal problems in wireless networks. IEEE Transactions on Wireless Communications 11 (11) 4204-4213.

[89] Kosch, T., Adler, C. J., Eichler, S., Schroth, C., \& Strassberger, M. (2006). The scalability problem of vehicular ad hoc networks and how to solve it. IEEE Wireless Communications 13 (5) 22-28.

[90] Raya, M., \& Hubaux, J. P. (2007). Securing vehicular ad hoc networks. Journal of computer security 15 (1) 3968.

[91] Ranjan, P., \& Ahirwar, K. K. (2011). Comparative study of vanet and manet routing protocols. In: Proc. of the In 
ternational Conference on Advanced Computing and Communication Technologies (ACCT 2011), pages 517-523. January 2011.

[92] Bilstrup, K. S., Uhlemann, E., \& Strom, E. G. (2010). Scalability Issues of the MAC Methods STDMA and CSMA of IEEE 802.11 p When Used in VANETs. In: 2010 IEEE International Conference on Communications Workshops, pages 1-5. IEEE, May 2010.

[93] Engoulou, R. G., Bellaïche, M., Pierre, S., \& Quintero, A. (2014). VANET security surveys. Computer Communications 44 (2014) 1-13.

[94] Samara, G., Al-Salihy, W. A., \& Sures, R. (2010). Security analysis of vehicular ad hoc nerworks (VANET). In: 2010 Second International Conference on Network Applications, Protocols and Services, pages 55-60. IEEE, September 2010.

[95] Raw, R. S., Kumar, M., \& Singh, N. (2013). Security challenges, issues and their solutions for VANET. International journal of network security \& its applications 5 (5) 95.

[96] Xu, S., Guo, P., Xu, B., \& Zhou, H. (2013). QoS evaluation of VANET routing protocols. Journal of Networks 8 (1) 132.

[97] Chang, C. Y., Yen, H. C., \& Deng, D. J. (2015). V2V QoS guaranteed channel access in IEEE $802.11 \mathrm{p}$ VANETs. IEEE Transactions on Dependable and Secure Computing 13 (1) 5-17.
[98] Olariu, S., \& Weigle, M. C. (2009). Vehicular networks: from theory to practice. Chapman and Hall/CRC. 2009.

[99] Amici, R., Bonola, M., Bracciale, L., Rabuffi, A., Loreti, P., \& Bianchi, G. (2014). Performance assessment of an epidemic protocol in VANET using real traces. Procedia Computer Science 40 (2014) 92-99.

[100] Vinel, A., Vishnevsky, V., \& Koucheryavy, Y. (2008). A simple analytical model for the periodic broadcasting in vehicular ad-hoc networks. In: 2008 IEEE Globecom Workshops, pages 1-5. IEEE, November 2008.

[101] Ernst, T., \& De La Fortelle, A. (2006). Car-to-Car and Car-to-Infrastructure Communication System based on NEMO and MANET in IPv6. In: Intelligent Transportation Systems World Congress. October 2006.

[102] Fujimoto, R. M., Perumalla, K., Park, A., Wu, H., Ammar, M. H., \& Riley, G. F. (2003). Large-scale network simulation: how big? how fast?. In: 11th IEEE/ACM International Symposium on Modeling, Analysis and Simulation of Computer Telecommunications Systems (MASCOTS 2003), pages 116-123. IEEE, October 2003.

[103] Camp, T., Boleng, J., \& Davies, V. (2002). A survey of mobility models for ad hoc network research. Wireless communications and mobile computing 2 (5) 483-502.

[104] Chaqfeh, M., Lakas, A., \& Jawhar, I. (2014). A survey on data dissemination in vehicular ad hoc networks. Vehicular Communications 1 (4) 214-225. 